Article

\title{
Switching LPS to LED Streetlight May Dramatically Reduce Activity and Foraging of Bats
}

\author{
Christian Kerbiriou ${ }^{1,2, *(0)}$, Kévin Barré ${ }^{1,2}{ }^{1}$, Léa Mariton ${ }^{1,2}$, Julie Pauwels ${ }^{1}$, Georges Zissis ${ }^{3}$ (1) \\ Alexandre Robert ${ }^{1}$ and Isabelle Le Viol ${ }^{1,2}$ \\ 1 Centre d'Ecologie et des Sciences de la Conservation (CESCO UMR 7204), Sorbonne Université, MNHN, \\ CNRS, 75005 Paris, France; kevin.barre@mnhn.fr (K.B.); lea.mariton@mnhn.fr (L.M.); \\ jul.pauwels@hotmail.com (J.P.); alexandre.robert@mnhn.fr (A.R.); isabelle.leviol@mnhn.fr (I.L.V.) \\ 2 Centre d'Ecologie et des Sciences de la Conservation (CESCO, UMR 7204, CNRS, MNHN, \\ Sorbonne-Université, MNHN, Station marine, 29900 Concarneau, France \\ 3 LAPLACE UMR 5213 CNRS-INPT-UT3, Université de Toulouse, 118 route de Narbonne, 31062 Toulouse \\ CEDEX 9, France; georges.zissis@laplace.univ-tlse.fr \\ * Correspondence: christian.kerbiriou@mnhn.fr
}

Received: 28 March 2020; Accepted: 20 April 2020; Published: 24 April 2020

\begin{abstract}
Artificial light at night is considered a major threat to biodiversity, especially for nocturnal species, as it reduces habitat availability, quality, and functionality. Since the recent evolution in light technologies in improving luminous efficacy, developed countries are experiencing a renewal of their lighting equipment that reaches its end-of-life, from conventional lighting technologies to light emitting diodes (LEDs). Despite potential cascading impacts of such a shift on nocturnal fauna, few studies have so far dealt with the impact of the renewal of street lighting by new technologies. Specifically, only one study, by Rowse et al.2016, examined the effects of switching from widely used low pressure sodium (LPS) lamps to LEDs, using bats as biological models. This study was based on a before-after-control-impact paired design (BACIP) at 12 pairs in the UK, each including one control and one experimental streetlight. If Rowse et al. 2016 showed no effect of switching to LEDs streetlights on bat activity, the effects of respective changes in light intensity and spectrum were not disentangled when testing switch effects. Here, we conduct a retrospective analysis of their data to include these covariates in statistical models with the aim of disentangling the relative effects of these light characteristics. Our re-analysis clearly indicates that the switches in spectrum and in intensity with replacement of LPS with LED lamps have significant additive and interactive effects, on bat activity. We also show that bat activity and buzz ratio decrease with increasing LED intensity while an opposite effect is observed with LPS lamps. Hence, the loss or the gain in bat activity when lamp types, i.e., spectrum, are switched strongly depends on the initial and new lamp intensities. Our results stress the need to consider simultaneously the effects of changes in the different lights characteristics when street lighting changes. Because switches from LPS to LED lamps can lead to an increase in light intensity, such technological changes may involve a reduction of bat activity in numerous cases, especially at high LED intensities. Since we are currently at an important crossroad in lighting management, we recommend to limit LED intensity and improve its spectral composition toward warmer colors to limit potential deleterious impacts on bat activity.
\end{abstract}

Keywords: artificial light at night; light pollution; bat activity; LED streetlight; Chiroptera

\section{Introduction}

Light pollution induced by the widespread use of artificial light at night (ALAN) is a global pressure on the ecosystem, affecting $23 \%$ of the global land surface ( $88 \%$ of Europe [1]) and expanding 
at an annual rate of $6 \%$ worldwide [2]. As ALAN alters the natural periodicity of day and night, it can disrupt the circadian and seasonal rhythms of both diurnal and nocturnal species. This pressure can affect individual fitness, sexual selection, and reproductive success [3-5]. In addition, species responses to ALAN are driven by repulsion/attraction behaviors, thereby artificial lighting can alter the movement and distribution of species at multiple spatial scales [6-9]. Taken together, ALAN effects can dramatically affect biological communities [10,11] and ecosystem functions [12].

ALAN also consumes $19 \%$ of total global electricity and accounts for $1900 \mathrm{Mt}$ of $\mathrm{CO}_{2}$ emissions per year [2]. Thus, a current major challenge in land-use planning involves designing outdoor lighting strategies that save energy and reduce $\mathrm{CO}_{2}$ emissions while limiting negative effects on biodiversity [2]. In the European Union, the most widely used streetlamp types are sodium vapor lamps (high pressure sodium, HPS and low pressure sodium, LPS), metal halide (MH), and high pressure mercury vapor lamps (HPM), representing respectively $37 \%, 36 \%$, and $27 \%$ sales for the period 2004-2007 [13]. However, since the European Eco-Design Directive (245/2009), and according to the recent evolution of light technologies, developed countries are experiencing a renewal of their lighting equipment that reaches its end-of-life, from conventional lighting technologies to light emitting diodes (LEDs) [14]. Specifically, LEDs have a high luminous efficacy (i.e., amount of energy needed to produce visible light in lumen per watt), and thus offer great opportunities to save energy and limit $\mathrm{CO}_{2}$ emissions [15]. In addition, conventional lighting technologies are being progressively phased out from the market because of their lower energetic efficiency [13]. This change is occurring concomitantly with the increasing cost-effectiveness of energy-efficient LEDs, representing so far approximately $7 \%$ of the European market [16]. This "breakthrough" lighting technology is an opportunity to drastically reduce the energy consumption of lighting compared to existing conventional lighting technologies, while allowing a greater flexibility in the control of the light environment as well as reducing maintenance costs [14]. However, this technology shift is accompanied by a change in light intensity and spectrum [14,17]. Indeed, both warm and cold white LEDs (2700 K and $4000 \mathrm{~K}$, respectively) present an important peak of emissions in blue and ultraviolet (UV) wavelengths, which induces physiological disruption affecting animals [18-20], and is responsible for the flight-to-light behavior of insects [21]. Thus, the expected massive deployment of this technology in public outdoor lighting raises major concerns regarding its potential impacts on biodiversity.

Strictly nocturnal animals such as microchiropteran bats are particularly likely to be affected by ALAN, since they may be exposed to it during their entire activity period. In addition, microchiropteran bats present contrasting responses to ALAN according to their flight abilities and foraging strategies [22]. While slow-flying gleaning bat species avoid illuminated areas $[9,23]$, common fast-flying aerial and hawking species such as Pipistrellus spp. forage for insects in open areas and are able to forage at the vicinity of streetlights that provide a more predictable insect biomass [22-24]. It is known that HPS lights attract moths, because of the presence of UV wavelengths (Figure 1), while LPS lights of the same intensity (not producing UV light) attract less moths [25]. Such differences in bat prey attractiveness impact in turn bat behavior. However, bats also have to deal with a trade-off that includes the benefits of foraging close to streetlights and the drawback of increased predation risk by exposure to light [26]. Such a trade-off can also induce a light avoidance behavior, which was detected regardless of the lamp spectrum [27] and even at low level of light illuminance [24,28]. In this context, we hypothesize that a switch from conventional lighting technologies to LEDs may produce contrasted effects on moth attraction and in turn on predators such as fast-flying bat species. Thus, the consequences of a renewal of street lighting on bat depend on changes in spectral composition and changes in the various components of light intensity (here, two aspects of intensity are considered: power (watts) and illuminance (lux), see Supplementary Material 1), it is thus not trivial to predict whether the renewal will conduct to an increase or a decrease in bat activity under streetlights. 
a

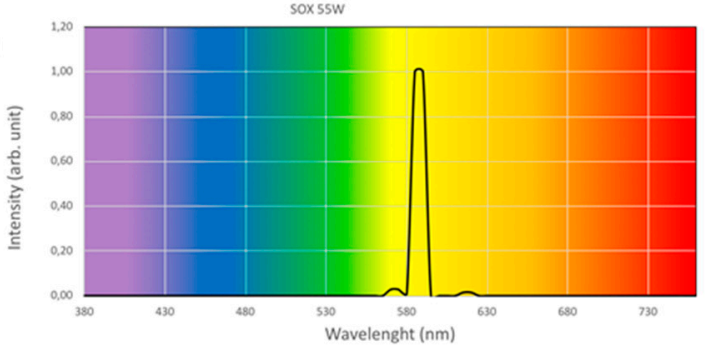

C

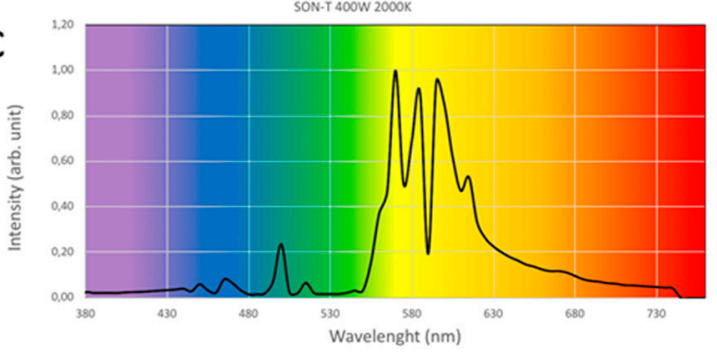

LEO LUXEON UXX8PW2:

e

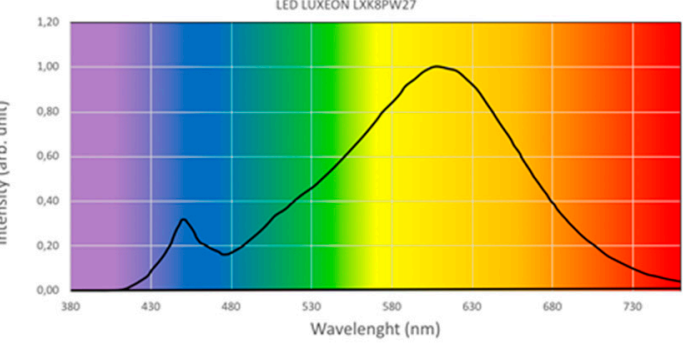

b

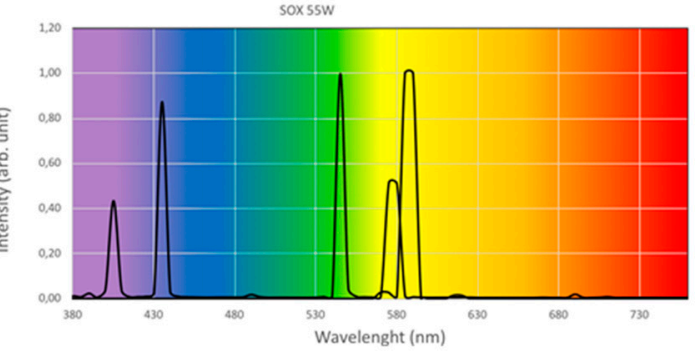

d

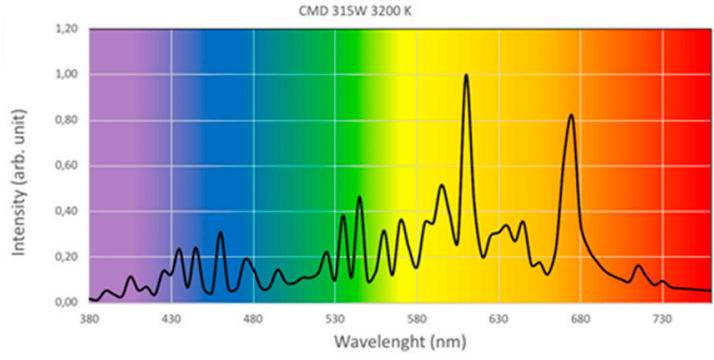

LEO NICHIA NWSL 4000K

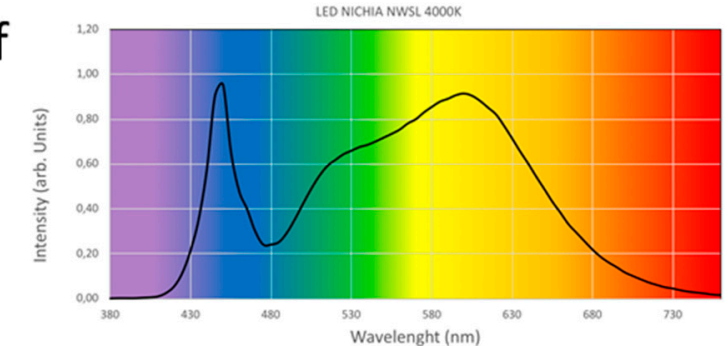

Figure 1. Spectra (visible domain 360-780 nm) of some commonly used lamps for outdoor lighting systems. Luminous intensities are normalized to the maximum value: (a) low pressure sodium (LPS) lamp (under ban due to eco-conception rules); (b) mercury high pressure lamp (MV) (under ban); (c) high pressure sodium lamp (HPS); (d) ceramic metal halide lamp (MH); (e) warm white light emitting diodes (LED) ( $2700 \mathrm{~K})$; (f) cool white LED (4000 K). Spectral data are measured by LAPLACE laboratory (private communication).

This renewal of street lighting by new technologies is happening worldwide. However, despite its potential cascading impacts on nocturnal fauna, few studies have so far dealt with the impacts of such a shift. Due to the lack of published studies, conducting a meta-analysis on this issue is not an option nowadays. Hence, all published works get close attention and the message conveyed can be viewed as a direct example to follow. In this context, Rowse et al. [17] set up one of the first in situ experiments to investigate the effect of a switch from commonly used LPS to LED lamps on microchiropteran bat activity. LPS and LED lamps are in that case, as in common practices (i.e., common sense for practitioners), mainly distinguished according to the most important change in their characteristics, i.e., in their spectrum. LPS lamps emit narrow-band spectrum with a single peak of energy in the yellow range ( 1807 K, Figure 1a), while LEDs used in this experiment were cool and neutral white emitting lamps (4000-5700 K), with a significant peak of blue emissions (Figure 1e,f). Thus, as insects are more attracted to short wavelengths such as blue and UVs than longer wavelengths such as yellow [21], it would be expected to find a positive effect of a switch from LPS to LEDs on the foraging activity of so-called "light-attracted" fast-flying species. To test this hypothesis, the authors of this study did a before-after-control impact paired design (BACIP) at 12 pairs in four UK counties. Each pair consisted in two sites of existing streetlights, with one control site remaining LPS throughout the study, and one experimental site switching from LPS to LED ([17] for complete description of the experiment). One of the strengths of this study lies in the fact that the authors monitored the effect of a real-life switch from LPS to LED streetlights performed by local authorities. Thus, their experiment corresponded 
to both ecological and public lighting realities. However, they did not control for lamp parameters that could potentially act as confounding effects in their study. In particular, although they intended to pair control and experimental streetlights at each site with similar height (m), and with similar lamp characteristics: light intensity (two metrics: output power (watts) and illuminance received by horizontal surface (lux)), there were still drastic differences in light illuminance and power output between the LPS lamps and the LEDs they were replaced by. It is, however, well known that light intensity is an important factor that can influence bat activity [24,28].

In their study, Rowse et al. [17] did not detect any effect of the switch from LPS to LED lamps on bat activity. However, as several light intensity characteristics (i.e., power and illuminance) changed between the "before" and "after" phases, we believe it is necessary to include the influence of those characteristics in statistical models. In addition, we also believe that using generalized linear mixed-effects models (GLMMs) is a more robust approach than the non-parametric approaches used by Rowse et al. [17] because GLMMs can directly use the information of bat activity abundance (i.e., the response variable) through error distribution adapted for count data with potential over-dispersion [29]. Hence, we conducted a retrospective analysis of Rowse et al.'s data [17] using an alternative approach aiming at disentangling the relative effects of light spectrum and intensity (i.e., power and illuminance) on bat activity following a switch from LPS to LED lamps.

According to the changes in spectrum composition, the switch from LPS to LED lamps will increase the amount of short wavelengths, and in return, contribute to attract much more insects [30]. We thus hypothesize that it will increase the activity of light-tolerant bats. However, bats are also sensitive to light intensity [28] due to the potential risk of predation exposure [31,32]. In this context, we expect that differences in bat activity generated by the switch from LPS to LED lamps will also depend on light intensity. In addition, LED light being closer to daylight characteristics, the increase in light intensity under LED lamps could lead to greater perception of the potential risk of predation exposure than LPS. The net result on bat activity (increase or decrease) will depend on a tradeoff between the risk of predation exposure and the increase in prey resource. Therefore, we hypothesize that bat activity will increase under LED lamps when light intensities are low, while it would decrease under high light intensities.

\section{Material and Methods}

\subsection{Biological Model}

Bats are increasingly threatened worldwide [33]. At the very local scale (i.e., the streetlight scale), some bats are able to feed on moths and flies attracted by streetlamps, these species named "light-tolerant species" are mainly fast-flying aerial hawking species (i.e., those in the genera Eptesicus, Nyctalus, and Pipistrellus). These species may benefit locally from the amount of prey [22]. In contrast, some species systematically avoid lit areas when commuting [8] and foraging [22]. These species, considered as "light-intolerant species", mainly include slow-flying bat species that avoid open areas such as Myotis spp. and Rhinolophus spp. Thus, artificial light may potentially intensify "interspecific competition for food" between rare species such as $R$. hipposideros and common species such as $P$. pipistrellus [34].

\subsection{Bat Activity}

According to their foraging strategy during the reproduction period, (i.e., individuals foraging around maternity roost $[35,36]$ using commuting corridors), the assessment of impact of anthropogenic pressures on bat relative abundance should favor in situ experiments that take into account landscape constraints. Acoustic recorders that allow users to measure bat activity, often considered as a proxy of relative abundance, were hence increasingly used over the last two decades in such studies, to test various anthropogenic pressures including artificial light at night at local scales $[8,23,37]$. Here, the proxy of bat activity was the number of bat passes over three consecutive nights [17]. Because bat 
passes were not detailed for each night, this group of three consecutive nights referred to a categorical variable hereafter named "date". This measure of bat passes allowed deriving five bat activity measures: the total number of bat passes, the number of bat passes for a given species (P. pipistrellus, P. pygmaeus, and Nyctalus spp) and the feeding buzz ratio of P. pipistrellus. Before catching an insect, bats produce particular echolocation calls, named buzzes [38]. The buzz ratio (i.e., the proportion of bat passes that included feeding buzzes) can reveal substantial information about capture success and can be used as an indirect proxy of bat's prey density [39].

\subsection{Experimental Set-up and Variation in Power and Illuminance of Lamps at Experimental Sites}

In order to investigate the impact of a switch from LPS to LED streetlights on bat activity, Rowse et al. [17] performed a before-after-control-impact paired design (BACIP), at 12 pairs across southern England. Each pair include one experimental lighting column (switch from LPS to LED) and one control lighting column (remaining LPS throughout the study). Control lighting columns (hereafter named control) were selected in landscapes where LPS lights remained the dominant lighting type throughout the study. Experimental lighting columns (hereafter named experimental) were selected in landscapes where LPS lights were the dominant lighting type before the switch-over and where LED were the dominant lighting type after the switch-over (for more details on the characteristics of sampled lighting columns see [17]). The LED lamps (hereafter name LED) studied were a combination of neutral and cool LED lights (4000-5700 K, see Figure 1e,f for spectrum composition). An exploration of landscape composition and streetlight column characteristics among sites using principal correspondence analysis confirmed the absence of the site with an obvious peculiar composition (see Supplementary Material 2)

Because bat activity measure is linked to prey invertebrate availability, and in turn, weather conditions [40-42], weather conditions have to be consequently taken into account in the design of in situ experiments. In order to disentangle the effects of a switch from LPS to LED on bat activity from the effects of weather conditions, Rowse et al. [17] sampled the two recording sites of a pair (treatment and control) during the same night. Recordings were made a minimum of seven days (mean 14.9 days, s.d. \pm 5.3 days) after the switch-over, with the aim to enable the bats to adjust to the new lights [17].

As Rowse et al. [17] worked on the switch of streetlights from LPS to LED performed by local authorities, they could not define themselves (i) the date of switch-over, thus leading to a staggering of the recording period from May to October 2014; and (ii) the new lamp characteristics. Concerning the first point, the staggering of the recording period from May to October is not an optimal sampling because bat activity changes dramatically during this timeframe [43]. Concerning the second point regarding new lamp characteristics, it is much more problematic, because, in addition to change in spectrum, the switch from LPS to LED resulted in drastic changes in light intensity (power and illuminance) of streetlamps (Table 1).

Table 1. Variations in power and illuminance at Rowse et al.'s study [17]. Variations were computed as the differences between the power/illuminance of low pressure sodium (LPS) in experimental before the switch-over and the power/illuminance of LED after the switch-over.

\begin{tabular}{cccc}
\hline Light Intensity & Mean $( \pm$ SE) & Minimum & Maximum \\
\hline Changes of power (watts) & $-10.6 \pm 3.8(-40 \%)$ & $-21(-61 \%)$ & $+16(+18 \%)$ \\
Changes of illuminance (lux) & $+17.7 \pm 8.5(+259 \%)$ & $-21(-51 \%)$ & $+64(+1800 \%)$ \\
\hline
\end{tabular}

Consequently, we believe it is important to disentangle the effects of changes in these characteristics (illuminance and power) from changes in lamp type (spectrum) on bat activity to fully assess the effects of switching from LPS to LED. 


\subsection{Statistical Analyses}

2.4.1. Preliminary Analysis 1: Analysis without Taking Account Changes in Light Intensity (Power and Illuminance)

Since we changed the conceptual framework of statistics (from non-parametric test to generalized linear modeling), firstly we performed similar analysis as Rowse et al. [17] (i.e., without taking into account changes in light intensity). Using the generalized linear mixed-effects model (GLMM; function and R package glmmTMB [44]), we also found qualitatively similar results as Rowse et al. [17] found using non-parametric tests, except for buzz ratio: our modeling allowed detecting a significant decrease in buzz ratio associated with the switch from LPS to LED occurring (see details in Supplementary Material 3).

2.4.2. Preliminary Analysis 2: Evaluation of the Influence of Intensity (Power and Illuminance) on Bats Activity

We assessed the relative importance of illuminance and power variables on bat activity compared to other explanatory variables (height, dist. wood, dist. water, dist. grass) using generalized linear modeling or hierarchical partition of the variance applied on the Rowse et al.'s dataset [17]. We confirmed the correlation between bat activity and power and illuminance (see Supplementary Material 4).

2.4.3. Disentangling the Relative Effects of Light Spectrum and Intensity (i.e., Power and Illuminance) on Bat Activity Following the Switch from LPS to LED Lamps

According to the two preliminary findings, i.e., (i) the correlation between bat activity and power and illuminance, which is congruent with the literature [24,28]; and (ii) the changes in power and illuminance between the before and after stages for experimental lighting columns (Table 1), we believe that including illuminance and power covariates in the statistical analyses is necessary to assess the effects of the lamp type per se (LPS and LED, i.e., major changes in spectrum) on bat activity. When reanalyzing data, we performed GLMM using as response variable of the number of bat passes, as explanatory variables of the lamp type (LPS versus LED) and the intensity (power or illuminance) as well as the interaction between lamp type and illuminance or power. In addition, we used a nested random effect (date within pairs) to account for the structure of the data (each site, i.e., a pair, consisted of a control and an experimental recording site sampled the same date before and the same date after). It should be noted that date was a categorical variable used to group data recorded on the same date, but was not informative as to the actual date of sampling. Because power and illuminance were obviously correlated (Spearman's rho $=0.64$, [45]), we performed independent modelings: one included power while the second included illuminance. According to the nature of the response variable (count of bat passes) and potential over-dispersion, we performed modelings using a negative binomial distribution (link $=\log$ ) [29], except for feeding buzz ratios, for which we used a binomial distribution (link $=$ logit). Thus, our statistical models were structured as follows:

$$
\text { Bat Activity } \sim \text { Lamp Intensity } \times \text { Lamp Type }+(1 \mid \text { Pair/Date })
$$

where Bat activity was (i) the number of passes for a given species, (ii) the feeding buzz ratio or (iii) a total number of bat passes, Lamp intensity was either the power or the illuminance variable and Lamp type referred to the spectrum (LPS or LED).

It is worth noting that in the data of Rowse et al. [17], bat activity may have been strongly influenced by the season (from May to October), which may have generated a high degree of heterogeneity in the results. However, the paired experimental design and the structure of the statistical model (random "pair" effect) make it possible to incorporate this variation without compromising the statistical power of the tests because the two measurements from the same pair (control and experimental sites) were always spatially close and were recorded simultaneously. 
A total bat activity could be strongly driven by species identity (because of differences of local abundances between species or specific distances of detection [46], some species can have more weight than another can). Instead of summing the activity of the different species, we thus added a nested random effect on the species to all models with total number of bat passes as the response variable. Finally, we checked for over-dispersion and for homogeneity of variance by visual inspection of residuals [47].

\section{Results}

When the lamp type effect was modeled using power as the covariate, we found that LED lamps increased the total bat activity, the Nyctalus spp. Activity, and the buzz ratio as compared to LPS. Overall, power has a negative effect on Pipistrellus pipistrellus activity and buzz ratio (Table 2). The relationship between bat activity and power significantly differed between LPS and LED lamps for total bat activity, the buzz ratio, and species activity measures except for Pipistrellus pygmaeus. Specifically, increasing power tended to increase bat activity with LPS lamps, while it tended to decrease bat activity with LED lamps (Table 2; Figure 2).

Table 2. Effects of the type of lamp (LPS versus LED), the lamp intensity (illuminance or power), and their interaction on bat activity. The estimates of LampLPS are the difference in bat activity between LPS lights and LED lights placed as intercept (i.e., a negative estimate indicates that bat activity is lower with LPS compared to LED for a given light intensity). The estimates of the interaction (LampLPS:Lamp intensity) correspond to the difference of slope between the two regressions (bat activity $\sim$ Lamp intensity) according to the lamp type (i.e., LPS versus LED).

\begin{tabular}{|c|c|c|c|c|c|}
\hline \multicolumn{2}{|c|}{ Bat Activities } & \multicolumn{2}{|c|}{ Illuminance } & \multicolumn{2}{|c|}{ Power } \\
\hline & & Estimate $\pm \mathrm{SE}$ & $p$-Value & Estimate $\pm \mathrm{SE}$ & $p$-Value \\
\hline \multirow{4}{*}{ Total bat activity } & Intercept & $3.670 \pm 0.917$ & $<0.001$ & $3.713 \pm 0.898$ & $<0.001$ \\
\hline & LampLPS & $-0.733 \pm 0.393$ & 0.062 & $-0.988 \pm 0.456$ & 0.030 \\
\hline & Lamp intensity & $0.001 \pm 0.007$ & 0.896 & $0.001 \pm 0.010$ & 0.945 \\
\hline & LampLPS:Lamp intensity & $0.021 \pm 0.007$ & 0.003 & $0.022 \pm 0.010$ & 0.029 \\
\hline \multirow{4}{*}{$\begin{array}{l}\text { Pipistrellus } \\
\text { pipistrellus }\end{array}$} & Intercept & $6.760 \pm 0.586$ & $<0.001$ & $6.584 \pm 0.522$ & $<0.001$ \\
\hline & LampLPS & $-1.168 \pm 0.566$ & 0.039 & $-0.732 \pm 0.625$ & 0.241 \\
\hline & Lamp intensity & $-0.024 \pm 0.009$ & 0.005 & $-0.033 \pm 0.012$ & 0.004 \\
\hline & LampLPS:Lamp intensity & $0.027 \pm 0.010$ & 0.008 & $0.030 \pm 0.014$ & 0.033 \\
\hline \multirow{4}{*}{$\begin{array}{c}\text { Pipistrellus } \\
\text { pygmaeus }\end{array}$} & Intercept & $2.180 \pm 0.935$ & 0.020 & $2.578 \pm 0.799$ & 0.001 \\
\hline & LampLPS & $-0.318 \pm 0.922$ & 0.730 & $-1.248 \pm 0.918$ & 0.174 \\
\hline & Lamp intensity & $0.027 \pm 0.015$ & 0.080 & $0.031 \pm 0.016$ & 0.052 \\
\hline & LampLPS:Lamp intensity & $-0.001 \pm 0.017$ & 0.968 & $0.003 \pm 0.018$ & 0.886 \\
\hline \multirow{4}{*}{ Nyctalus spp. } & Intercept & $2.093 \pm 0.786$ & 0.008 & $2.335 \pm 0.808$ & 0.004 \\
\hline & LampLPS & $-0.773 \pm 0.547$ & 0.158 & $-1.578 \pm 0.712$ & 0.027 \\
\hline & Lamp intensity & $-0.001 \pm 0.010$ & 0.886 & $-0.014 \pm 0.017$ & 0.403 \\
\hline & LampLPS:Lamp intensity & $0.032 \pm 0.009$ & 0.001 & $0.051 \pm 0.014$ & $<0.001$ \\
\hline \multirow{4}{*}{ Feeding buzz ratio } & Intercept & $-0.931 \pm 0.237$ & $<0.001$ & $-0.662 \pm 0.262$ & 0.012 \\
\hline & LampLPS & $-1.681 \pm 0.188$ & $<0.001$ & $-2.415 \pm 0.294$ & $<0.001$ \\
\hline & Lamp intensity & $-0.052 \pm 0.004$ & $<0.001$ & $-0.132 \pm 0.009$ & $<0.001$ \\
\hline & LampLPS:Lamp intensity & $0.066 \pm 0.004$ & $<0.001$ & $0.154 \pm 0.010$ & $<0.001$ \\
\hline
\end{tabular}



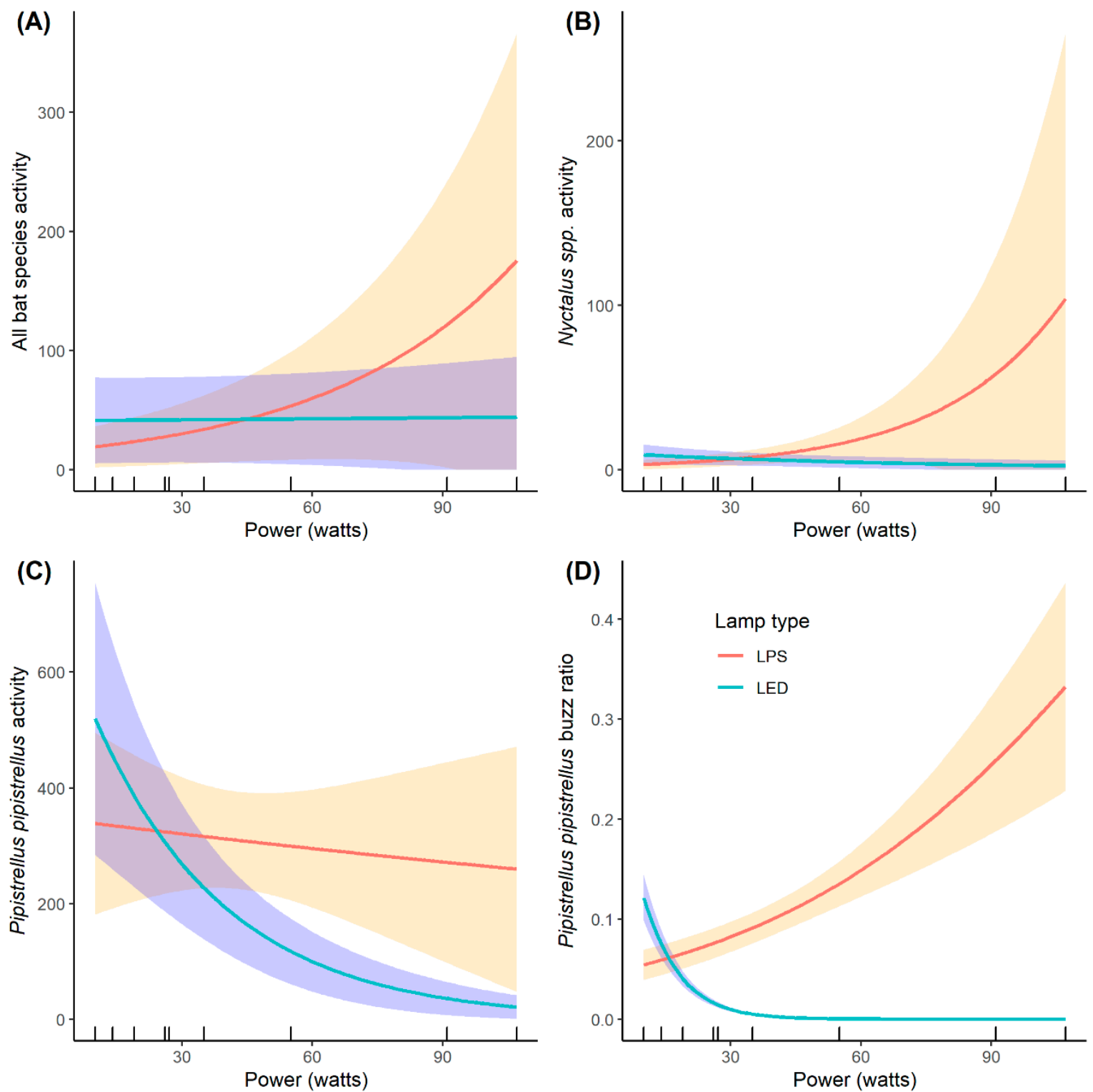

Figure 2. Predicted bat activity (total bat activity could (A), Nyctalus spp. Activity (B), Pipistrellus pipistrellus activity (C) and P. pistrellus buzz ratio (D)) as a function of the light power according to the lamp type (light emitting diodes (LED) and low pressure sodium (LPS)). Results come from interactions presented in the light power modeling (right side of Table 2).

When the lamp type effect was modeled using illuminance as the covariate, we found that LED lamps increased buzz ratio and activity of P. pipistrellus as compared to LPS. Overall, like power, the illuminance has a negative effect on P. pipistrellus activity and the buzz ratio (Table 2). The relationship between bat activity and illuminance significantly differed between LPS and LED lights for total bat activity, the buzz ratio, and species activity except for P. pygmaeus as well. As in the power analysis, increasing illuminance increased bat activity with LPS lamps, while it decreased it with LED lamps (Table 2; Figure 3). 

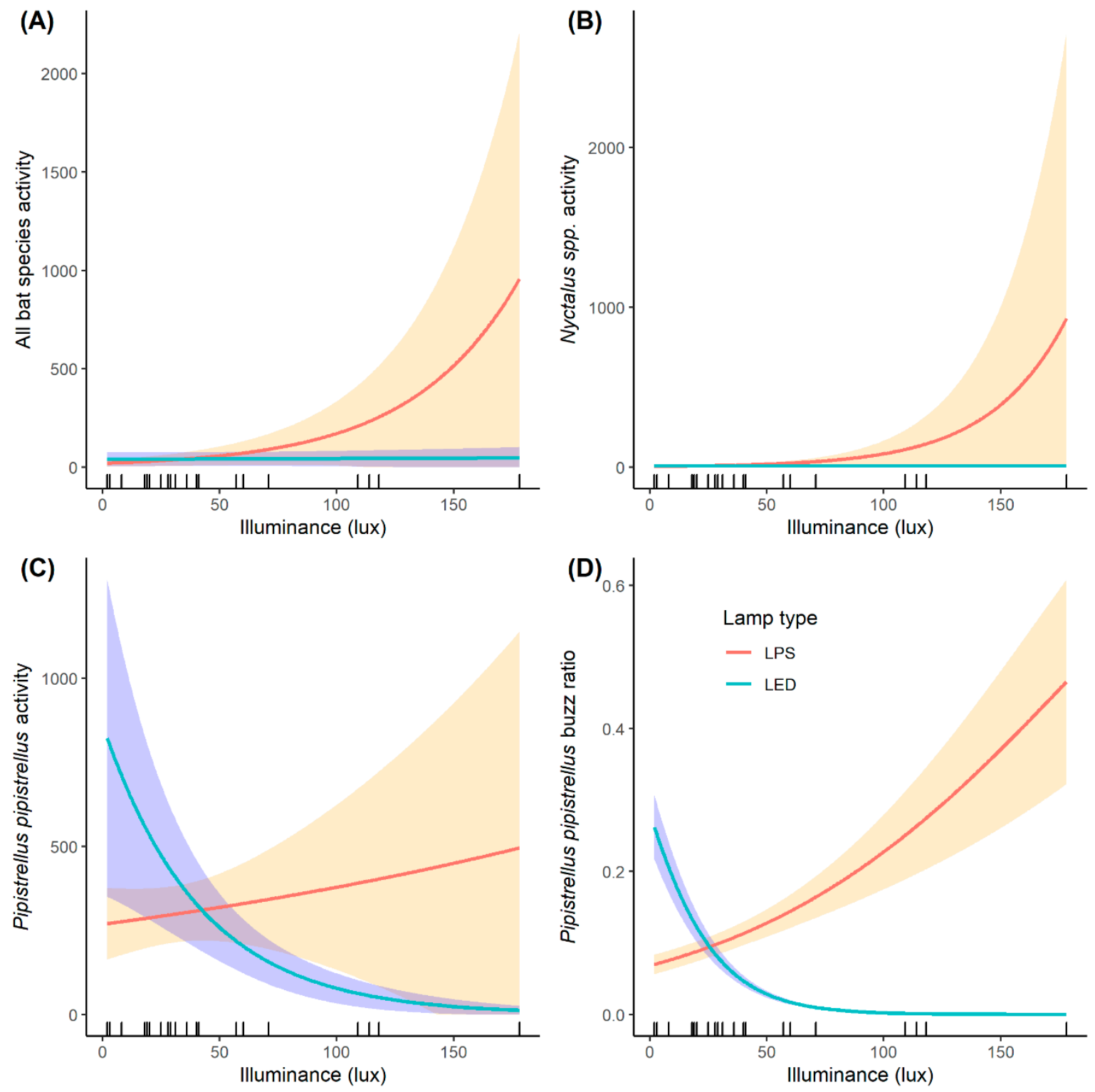

Figure 3. Predicted bat activity (total bat activity could (A), Nyctalus spp. Activity (B), Pipistrellus pipistrellus activity (C) and P. pistrellus buzz ratio (D) as a function of the light illuminance according to the lamp type (light emitting diodes (LED) and low pressure sodium (LPS)). Results come from interactions presented in the light illuminance modeling (left side of Table 2).

\section{Discussion}

In contrast to the study of Rowse et al. [17], which concluded that the switch from LPS to LED lamps had no effect on bats, our analyses indicate that the switch from LPS to LED lamps (i.e., in spectrum) has a significant effect on bat activity, although this effect strongly depends on light intensity level. The main reason for such discrepancy between our conclusion and that of Rowse et al. (2016) comes from the inclusion of changes in light intensity in our statistical modeling. The loss or gain in activity that results from this switch in spectrum strongly depends on both initial and new lamp intensities: at the lowest intensities, bat activities were higher near LED than LPS, while for high intensities it was the opposite (i.e., bat activity and buzz ratio decrease with increasing LED intensity, while an opposite effect was observed with LPS lamps). Because switches from LPS to LED lamps can lead to an increase in illuminance, these results indicate that such technological changes may involve a reduction of bat activity in numerous cases, especially at high LED intensities. 
According to the limited number of sites sampled, these results should be treated with caution and we encourage repeating such study. In addition, these results should also be used with caution as they are based on whole-night activity metrics, which do not provide information on the full range of possible impacts. Indeed, artificial light also disrupts the behavior, phenology, and physiology of individuals [48-50], which should be assessed with more accurate temporal resolution. Unfortunately, this information was not available.

The interaction between spectrum and intensity reveals a trade-off between foraging opportunities and risks of exposure to predation when bats forage in a lit environment. On one hand, streetlight made up of lamp types with important proportion of blue or UV wavelengths (cool white LED, HPM, $\mathrm{MH}$, Figure 1), concentrate insects' preys [33] and therefore can be attractive for light tolerant bat species, but on the other hand, the increase of intensity may be perceived as an increase of the risk of exposure to predation $[33,34]$. Thus, the trade-off between the increase in prey amount and the increase of predation risk, both linked to the increase in light intensity, appears to be more profitable for bats under LPS than LED lamps. An assumption to explain this difference is that LED light is closer to daylight characteristics and is thus associated to a greater risk of predation exposure. Our results also confirmed the hypothesis that at low intensity, the direction of the effect of change in spectrum on bat activity—of light-tolerant bats—should depend on the amount of UV and of blue wavelengths as these parameters induce more phototaxis of flying insects [21]. At the lowest intensities, the switch from LPS to LED and hence the increase in amount of UV and of blue wavelengths, resulted indeed in an increase of bat activity. This result is also congruent with the study performed by Stone et al. [51] on the impact of the switch from LPS to white metal halid lamps. Such change resulted in an increase in the amount of UV and blue wavelengths emitted (Figure 1d) and led to an increase of light-tolerant bat activity (Pipistrellus pipistrellus, P. pygmaeus, and Nyctalus/Eptesicus spp.) [51]. In contrast, a decrease of light-tolerant bat activity should be expected for a switch from mercury vapor (MV) to LED lamps, because it will contribute to a decrease of the amount of UV and of blue wavelengths emitted (LED includes a lower amount of wavelengths attractive for insects (Figure 1e,f for LED compared to Figure $1 \mathrm{~b}$ for MV)). This result was found by Lewanzik and Voigt [52] who detected a decrease in bat activity when mercury vapor (MV) lamps were switched to LED lamps.

However, the observed increase or decrease in bat activity under streetlights consecutively to the renewal of conventional lights to LED should be carefully interpreted. Firstly, whatever the type of spectrum or light intensity, some bats species systematically avoid lit environments, particularly slow-flying species adapted to prey on insects in cluttered vegetation, such as Rhinolophus spp. and Myotis spp. $[8,9,23]$. Secondly, even for light tolerant species such as Pipistrellus pipistrellus, spatial scale has to be considered for biological interpretation of light effect. At a local scale, some bats species can be concentrated in illuminated areas rather than surrounding dark places because streetlights offer new and predictable foraging opportunities by attracting a large portion of the surrounding insect biomass $[25,53]$. However, the impact of ALAN could be considered as negative on both nocturnal insects and bats at a larger scale because it reduces prey availability for bats in surrounding unlit landscapes by massively aggregating preys at light sources and inducing high mortality of insect (so-called "vacuum cleaner effect", $[5,25,54])$. This is furthermore of particular concern as a national scale study in Great Britain showed that common species of moths have experienced rapid declines over the last 30 years [55]. This hypothesis of opposite effects of ALAN according to the spatial scale considered was confirmed by different studies (local scale: [23] vs. landscape scale: [6,56]). The studies carried out at the landscape-scale revealed negative effects of ALAN on the activity and probability of occurrence of four common species of bats: P. pipistrellus, P. kuhlii, E. serotinus, and N. leisleri, which are considered as « light attracted » species at the more local scale [22-24]. These hidden negative effects of ALAN at a landscape scale could also be explained by the fact that artificial lighting does not only influence species foraging behavior, but also reproduction and commuting behaviors [57], and landscape connectivity [7]. 
We are currently at an important crossroad in lighting management: (i) light pollution had been increasing drastically every year for several decades in developed countries and is expanding in developing ones $[2,58,59]$, and now (ii) lighting equipment reaches its end-of-life in developed countries. The increased cost-effectiveness of white-LEDs may contribute to an increase of ALAN through (i) the introduction of new artificial lighting sources in previously unlit areas, and (ii) the use of brighter light sources $[15,16]$. In this context, limiting the adverse impact of ALAN involves limiting the extent of lighting in natural habitats and sparsely urbanized habitats (removal of unnecessary light points), and maintaining areas of darkness in human-inhabited landscapes [15]. Such outdoor lighting planning requires to manage ALAN through five integrated levers of action. The two first levers raise the following questions: (i) within a landscape, which light points are necessary? (ii) during a night, what duration of lighting is necessary? Second, once areas and time periods that really need to be lit have been identified-for example for safety reasons-it should focus on (iii) the avoidance of unnecessary dispersion of light through precise directionality of the luminous flux, (iv) the drastic reduction of the proportion of UV and blue wavelengths in the spectral composition of the lamps [60], and (v) the reduction of the illuminance of light sources.

\section{Conclusions}

Our re-analysis clearly showed that the switches in both spectrum and intensity associated with the replacement of LPS with LED lamps strongly affected bat activity. We showed that bat activity and buzz ratio decreased with increasing LED intensity, while an opposite effect was observed with LPS lamps. Hence, the loss or the gain in bat activity when lamp types, i.e., spectrum, are switched, strongly depends on the initial and new lamp intensities. In particular, we showed that when LPS lamps are replaced by LEDs with high illuminance (i.e., $>25$ lux), bat activity and foraging activity are dramatically reduced. Such results stress the need to consider simultaneously the effects of changes of different light characteristics when a switch of street lighting occurs. Because switches from LPS to LED lamps can lead to an increase in light intensity, such technological change may involve a reduction of bat activity in numerous cases, especially at high LED intensities.

According to the current trend of renewal of lighting equipment, from conventional lighting technologies to LEDs that offer great opportunities to save energy and limit $\mathrm{CO}_{2}$ emissions, we recommend to pay close attention to reduce the amount of lowest wavelengths (i.e., blue) on the LED spectrum (for example warm white LED $(2500 \mathrm{~K})$ instead of cool white LED $(5000 \mathrm{~K})$ ) and reduce the lamp illuminance since both constitute main drivers of impacts on bats and their preys [30,37].

Supplementary Materials: The following are available online at http://www.mdpi.com/1424-2818/12/4/165/s1, Figure S1. Principal component analysis (R Pacakge ade4, function dudi.pca, Chessel D. \& Dufour AB) performed on landscape variables and streetlight column characteristics among sites (Ac: control lighting column of the pair A, Ae: experimental lighting column of the pair A). The streetlight characteristics included characteristics that did not change such as the lighting height (Height) and characteristics that changed during the switch such as power and illuminance: PowerBefore is the power (Watts) in site before the switch, PowerAfter, power after the switch (same typology for illuminance), ChangePower is the difference between the power of LPS in experimental site before the switch and the power of LED after the switch (same definition for the Changeilluminance). Landscape variables included the distance to a wooded area (m), Dist_Wood, the distance to freshwater (m) Dist_Water and the distance to grassland (m), Dist_Grass. (a) eigenvalues of the PCA, Figure S2. Predicted buzz ratios of $P$. pipistrellus at control (i.e., lit using LED lamps throughout both years of the experiment) and experimental sites (i.e., lit using LED lamps only the first year and LPS lamps only the second year) before and after the switch from LPS to LED lamps under experimental sites. Results come from the BACIP modeling, Figure S3. Percentage of total explained variance, Figure S4. Relationship between bat activity (log-transformed of the number of bat passes) and illuminance (lux) at the 24 LPS streetlights in control and experimental sites before the switch, Table S1. Estimates, standard errors (SE) and $p$-value of the bat activity at control (i.e., without change of LPS lights) and experimental sites (i.e., with LPS lights switched to LED lights) before and after LPS lights were switched to LED lights. Here, the 'reference' category (i.e., the intercept) is 'control' and is identified as a category of comparison for the other categories (here 'experimental'), Table S2. Effect of environmental variables on bat activities ( $\beta$ is the estimate of GLM), $p$-values were calculated using an ANOVA with a F-test for expressed. According to the need to adjust $p$-values for multiple comparisons, Bonferroni correction indicates that a $\alpha=0.05$ threshold level should be considered here as $\alpha=0.008$, thus significant $p$-values in regard to Bonferroni correction are indicated in 
bold, * indicated that error distribution used was a quasi-Poisson instead of a negative binomial due to problem of model convergence.

Author Contributions: Conceptualization, C.K.; Formal analysis, C.K., K.B., J.P., A.R. and I.L.V.; Investigation, C.K.; Methodology, C.K., K.B. and I.L.V.; Supervision, C.K.; Validation, C.K.; Visualization, C.K., G.Z.; Writing original draft, C.K.; Writing - review \& editing, C.K., C.B., L.M., J.P., G.Z., A.R. and I.L.V. All authors have read and agreed to the published version of the manuscript.

Funding: This research received no external funding.

Conflicts of Interest: The authors declare no conflict of interest.

\section{References}

1. Falchi, F.; Cinzano, P.; Duriscoe, D.; Kyba, C.C.M.; Elvidge, C.D.; Baugh, K.; Portnov, B.A.; Rybnikova, N.A.; Furgoni, R. The new world atlas of artificial night sky brightness. Sci. Adv. 2016, 2, e1600377. [CrossRef] [PubMed]

2. Hölker, F.; Moss, T.; Griefahn, B.; Kloas, W. The Dark Side of Light: A Transdisciplinary Research Agenda for Light Pollution Policy. Ecol. Soc. 2010, 15, 13. [CrossRef]

3. Hölker, F.; Wolter, C.; Perkin, E.K.; Tockner, K. Light pollution as a biodiversity threat. Trends Ecol. Evol. 2010, 25, 681-682. [CrossRef] [PubMed]

4. Navara, K.J.; Nelson, R.J. The dark side of light at night: Physiological, epidemiological, and ecological consequences. J. Pineal R. 2007, 43, 215-224. [CrossRef] [PubMed]

5. Rich, C.; Longcore, T. Ecological Consequences of Artificial Night Lighting; Island Press: Washington, DC, USA, 2006; p. 480.

6. Azam, C.; Le Viol, I.; Julien, J.F.; Bas, Y.; Kerbiriou, C. Disentangling the relative effect of light pollution, im;pervious surfaces and intensive agriculture on bat activity with a national-scale monitoring program. Landsc. Ecol. 2016, 31, 2471-2483. [CrossRef]

7. Laforge, A.; Pauwels, J.; Faure, B.; Bas, Y.; Kerbiriou, C.; Fonderflick, J.; Besnard, A. Reducing light pollution improves connectivity for bats in urban landscapes. Landsc. Ecol. 2019, 34, 793-809. [CrossRef]

8. Stone, E.L.; Jones, G.; Harris, S. Street Lighting Disturbs Commuting Bats. Curr. Biol. 2009, 19, $1123-1127$. [CrossRef]

9. Stone, E.L.; Jones, G.; Harris, S. Conserving energy at a cost to biodiversity? Impacts of LED lighting on bats. Glob. Chang. Biol. 2012, 18, 2458-2465. [CrossRef]

10. Davies, T.W.; Coleman, M.; Griffith, K.M.; Jenkins, S.R. Night-time lighting alters the composition of marine epifaunal communities. Biol. Lett. 2015, 11, 20150080. [CrossRef]

11. Minnaar, C.; Boyles, J.G.; Minnaar, I.A.; Sole, C.L.; Mckechnie, A.E. Stacking the odds: Light pollution may shift the balance in an ancient predator-prey arms race. J. Appl. Ecol. 2015, 52, 522-531. [CrossRef]

12. Bennie, J.; Davies, T.W.; Cruse, D.; Inger, R.; Gaston, K.J. Cascading effects of artificial light at night: Resource-mediated control of herbivores in a grassland ecosystem. Philos. Trans. R. Soc. B 2015, 370, 20140131. [CrossRef] [PubMed]

13. European Commission. The European GreenLight Programme Efficient Lighting Project Implementation Catalogue 2005-2009. 2011. Available online: https://publications.jrc.ec.europa.eu/repository/bitstream/ JRC62317/reqno_jrc62317_lb-na-24689-en.pdf (accessed on 27 March 2020).

14. Almeida, P.S.; Braga, H.A.C.; Dalla Costa, M.A.; Alonso, J.M. Offline Soft-Switched LED Driver Based on an Integrated Bridgeless Boost-Asymmetrical Half-Bridge Converte. IEEE Trans. Ind. Appl. 2015, 51, 761-769. [CrossRef]

15. Kyba, C.C.M.; Hänel, A.; Hölker, F. Redefining efficiency for outdoor lighting. Energy Environ. Sci. 2014, 7, 1806-1809. [CrossRef]

16. Update on the Status of LED Market. Publications Office of the European Union, 2014. Available online: https://publications.jrc.ec.europa.eu/repository/bitstream/JRC92971/jrc92971\%20online.pdf (accessed on 27 March 2020).

17. Rowse, E.G.; Harris, S.; Jones, G. The switch from low-pressure sodium to light emitting diodes does not affect bat activity at street lights. PLoS ONE 2016, 11, e0150884. [CrossRef] [PubMed]

18. Aubé, M.; Roby, J.; Kocifaj, M. Evaluating Potential Spectral Impacts of Various Artificial Lights on Melatonin Suppression, Photosynthesis, and StarVisibility. PLoS ONE 2013, 8, e67798. [CrossRef] 
19. Dominoni, D.M.; Quetting, M.; Partecke, J. Long-Term Effects of Chronic Light Pollution on Seasonal Functions of European Blackbirds (Turdus merula). PLoS ONE 2013, 8, e85069. [CrossRef]

20. Durrant, J.; Michaelides, E.B.; Rupasinghe, T.; Tull, D.; Green, M.P.; Jones, T.M. Constant illumination reduces circulating melatonin and impairs immune function in the cricket Teleogryllus commodus. PeerJ 2015, 3, e1075. [CrossRef]

21. van Langevelde, F.; Ettema, J.A.; Donners, M.; WallisDeVries, M.F.; Groenendijk, D. Effect of spectral composition of artificial light on the attraction of moths. Biol. Conserv. 2011, 144, 2274-2281. [CrossRef]

22. Rydell, J. Exploitation of insects around streetlamps by bats in Sweden. Funct. Ecol. 1992, 6, 744-750. [CrossRef]

23. Azam, C.; Kerbiriou, C.; Vernet, A.; Julien, J.F.; Bas, Y.; Plichard, L.; Maratrat, J.; Le Viol, I. Is part-night lighting an effective measure to limit the impacts of artificial lighting on bats? Glob. Chang. Biol. 2015, 21, 4333-4341. [CrossRef]

24. Lacoeuilhe, A.; Machon, N.; Julien, J.-F.; Le Bocq, A.; Kerbiriou, C. The influence of low intensities of light pollution on bat communities in a semi-natural context. PLoS ONE 2014, 9, e103042. [CrossRef]

25. Eisenbeis, G. Artificial night lighting and insects: Attraction of insects to streetlamps in a rural setting in Germany. In Ecological Consequences of Artificial Night Lighting; Rich, C., Longcore, T., Eds.; Island Press: Washington, DC, USA, 2006; pp. 281-304.

26. Rydell, J. Bats and Their Insect Prey at Streetlights. In Ecological Consequences of Artificial Night Lighting; Rich, C., Longcore, T., Eds.; Island Press: Washington, DC, USA, 2006; pp. 43-60.

27. Stone, E.; Zeale, M.R.K.; Newson, S.E.; Browne, W.J.; Harris, S.; Jones, G. Managing Conflict between Bats and Humans: The Response of Soprano Pipistrelles (Pipistrellus pygmaeus) to Exclusion from Roosts in Houses. PLoS ONE 2015, 10, e0131825. [CrossRef] [PubMed]

28. Azam, C.; Le Viol, I.; Bas, Y.; Zissis, G.; Vernet, A.; Julien, J.F.; Kerbiriou, C. Evidence for distance and illuminance thresholds in the effects of artificial lighting on bat activity. Landsc. Urban Plan. 2018, 175, 123-135. [CrossRef]

29. Zuur, A.; Ieno, E.N.; Walker, N.; Saveliev, A.A.; Smith, G.M. Mixed Effects Models and Extensions in Ecology with R; Springer: New York, NY, USA, 2009; pp. 322-342.

30. Owens, A.C.S.; Lewis, S.M. The impact of artificial light at night on nocturnal insects: A review and synthesis. Ecol. Evol. 2018, 11337-11358. [CrossRef] [PubMed]

31. Jones, G.; Rydell, J. Foraging strategy and predation risk as factors influencing emergence time in echolocating bats. Philos. Trans. R. Soc. B. 1994, 346, 445-455.

32. Rydell, J.; Entwistle, A.; Racey, A. Timing of Foraging Flights of Three Species of Bats in Relation to Insect Activity and Predation Risk. Oikos 1996, 76, 243-252. [CrossRef]

33. Mickleburgh, S.P.; Hutson, A.M.; Racey, P.A. A review of the global conservation status of bats. Oryx 2002, 36, 18-34. [CrossRef]

34. Arlettaz, R.; Godat, S.; Meyer, H. Competition for food by expanding pipistrelle bat populations (Pipistrellus pipistrellus) might contribute to the decline of lesser horseshoe bats (Rhinolophus hipposideros). Biol. Conserv. 2000, 93, 55-60. [CrossRef]

35. Robinson, M.F.; Stebbings, R.E. Home range and habitat use by the serotine bat, Eptesicus serotinus, in England. J. Zool. 1997, 243, 117-136. [CrossRef]

36. Safi, K.; König, B.; Kerth, G. Sex differences in population genetics, home range size and habitat use of the parti-colored bat (Vespertilio murinus, Linnaeus 1758) in Switzerland and their consequences for conservation. Biol. Conserv. 2007, 137, 28-36. [CrossRef]

37. Spoelstra, K.; van Grunsven, R.H.A.; Ramakers, J.J.C.; Ferguson, K.B.; Raap, T.; Donners, M.; Veenendaal, E.M.; Visser, M.E. Response of bats to light with different spectra: Light-shy and agile bat presence is affected by white and green, but not red light. Proc. R. Soc. Ser. B-Biol. Soc. 2017, 284, 1855. [CrossRef] [PubMed]

38. Obrist, M.K.; Boesch, R.; Flückiger, P.F. Variability in echolocation call design of 26 Swiss bat species: Consequences, limits and options for automated field identification with a synergetic pattern recognition approach. Mammalia 2004, 68, 307-322. [CrossRef]

39. Britton, A.R.; Jones, G. Echolocation behaviour and prey-capture success in foraging bats: Laboratory and field experiments on Myotis daubentonii. J. Exp. Biol. 1999, 202, 1793-1801. [PubMed]

40. Hayes, J.P. Temporal Variation in Activity of Bats and the Design of Echolocation-Monitoring Studies. J. Mam. 1997, 78, 21. [CrossRef] 
41. O'Donnell, C.F.J. Influence of season, habitat, temperature, and invertebrate availability on nocturnal activity of the New Zealand long-tailed bat (Chalinolobus tuberculatus). N. Z. J. Zool. 2000, 27, 207-221. [CrossRef]

42. Ciechanowski, M.; Zajac, T.; Bilas, A.; Dunajski, R. Spatiotemporal variation in activity of bat species differing in hunting tactics: Effects of weather, moonlight, food abundance, and structural clutter. Can. J. Zool. 2007, 85, 1249-1263. [CrossRef]

43. Newson, S.E.; Evans, H.E.; Gillings, S. A novel citizen science approach for large-scale standardised monitoring of bat activity and distribution, evaluated in eastern England. Biol. Conserv. 2015, 191, 38-49. [CrossRef]

44. Generalized Linear Mixed Models Using Template Model Builder. 2020. Available online: http://cran.unimuenster.de/web/packages/glmmTMB/glmmTMB.pdf (accessed on 27 March 2020).

45. Freckleton, R.P. On the misuse of residuals in ecology: Regression of residuals vs. multiple regression. J. Anim. Ecol. 2002, 71, 542-545. [CrossRef]

46. Kerbiriou, C.; Bas, Y.; Le Viol, I.; Lorrillière, R.; Mougnot, J.; Julien, J.F. Bat Pass Duration Measurement: An Indirect Measure of Distance of Detection. Diversity 2019, 11, 47. [CrossRef]

47. Zuur, A.; Ieno, E.N.; Elphick, C.S. A protocol for data exploration to avoid common statistical problems. Meth. Ecol. Evol. 2010, 1, 3-14. [CrossRef]

48. Dominoni, D.M.; Nelson, R.J. Artificial light at night as an environmental pollutant: An integrative approach across taxa, biological functions, and scientific disciplines. J. Exp. Zool. 2018, 329, 387-393. [CrossRef] [PubMed]

49. Polak, T.; Korine, C.; Yair, S.; Holderied, M.W. Differential effects of artificial lighting on flight and foraging behaviour of two sympatric bat species in a desert. J. Zool. 2011, 285, 21-27.

50. Boldogh, S.; Dobrosi, D.; Samu, P. The effects of the illumination of buildings on house-dwelling bats and its conservation consequences. Acta Chiropterol. 2007, 9, 527-534. [CrossRef]

51. Stone, E.L.; Wakefield, A.; Harris, S.; Jones, G. The impacts of new street light technologies: Experimentally testing the effects on bats of changing from low-pressure sodium to white metal halide. Philos. Trans. R. Soc. B 2015, 370, 20140127. [CrossRef] [PubMed]

52. Lewanzik, D.; Voigt, C.C. Transition from conventional to light-emitting diode street lighting changes activity of urban bats. J. Appl. Ecol. 2017, 54, 264-271. [CrossRef]

53. Perkin, E.K.; Hölker, F.; Tockner, K.; Richardson, J.S. Artificial light as a disturbance to light-naïve streams. Freshw. Biol. 2014, 59, 2235-2244. [CrossRef]

54. Grubisic, M.; van Grunsven, R.; Kyba, C.; Manfrin, A.; Hölker, F. Insect declines and agroecosystems: Does light pollution matter? Ann. Appl. Biol. 2018, 173, 180-189. [CrossRef]

55. Conrad, K.F.; Warren, M.S.; Fox, R.; Parsons, M.S.; Woiwod, I.P. Rapid declines of common, widespread British moths provide evidence of an insect biodiversity crisis. Biol. Conserv. 2006, 132, 279-291. [CrossRef]

56. Pauwels, J.; Le Viol, I.; Azam, C.; Valet, N.; Julien, J.F.; Bas, Y.; Lemarchand, C.; de Miguel, A.S.; Kerbiriou, C. Accounting for artificial light impact on bat activity for a biodiversity-friendly urban planning. Landsc. Urban Plan. 2019, 183, 12-25. [CrossRef]

57. Hale, J.D.; Fairbrass, A.J.; Matthews, T.J.; Davies, G.; Sadler, J.P. The ecological impact of city lighting scenarios: Exploring gap crossing thresholds for urban bats. Glob. Chang. Biol. 2015, 21, 2467-2478. [CrossRef]

58. Bennie, J.; Davies, T.W.; Inger, R.; Gaston, K.J. Mapping artificial lightscapes for ecological studies. Met. Ecol. Evol. 2014, 5, 534-540. [CrossRef]

59. Sánchez de Miguel, A.; Aubé, M.; Zamorano, J.; Kocifaj, M.; Roby, J.; Tapia, C. Sky Quality Meter measurements in a colour-changing world. Mon. Not. R. Astron. Soc. 2017, 467, 2966-2979. [CrossRef]

60. Gaston, K.J.; Davies, T.W.; Bennie, J.; Hopkins, J. REVIEW: Reducing the ecological consequences of night-time light pollution: Options and developments. J. Appl. Ecol. 2012, 49, 1256-1266. [CrossRef] [PubMed]

(C) 2020 by the authors. Licensee MDPI, Basel, Switzerland. This article is an open access article distributed under the terms and conditions of the Creative Commons Attribution (CC BY) license (http://creativecommons.org/licenses/by/4.0/). 